\title{
Análise do discurso politicamente incorreto na atual mídia humorística televisiva brasileira: o caso de entrevistas feitas por Danilo Gentili
} Analysis of the politically incorrect discourse on the current Brazilian humorous
television media: a study of interviews with Danilo Gentili

Gabriel Santana* Maria Virgínia Leal

RESUMO: Com base na Análise do Discurso, especialmente na corrente francesa $(\mathrm{AD})$, este trabalho tem como objetivo compreender a problemática envolvendo questões de Direitos Humanos e o humor politicamente incorreto na mídia televisiva. Mediante um corpus composto por discursos preconceituosos e, principalmente, de repúdio aos Direitos Humanos e ao politicamente correto em dois programas do humorista Danilo Gentili, buscaremos mostrar os discursos de enaltecimento do politicamente incorreto acrítico ${ }^{1}$ dentro do espaço televisivo brasileiro.

PALAVRAS-CHAVE: Análise do Discurso. Humor politicamente incorreto. Piadas. Direitos humanos. Danilo Gentili.

\begin{abstract}
Based on French Discourse Analysis, this work aims to comprehend the issue around Human Rights and the politically incorrect humor on television media. By a corpus composed by discourses that are biased and, specially, that neglect Human Rights and the politically correct from two TV-shows hosted by the humorist Danilo Gentili, we aim to show the signals of the uncritical politically incorrect exaltation discourses inside the Brazilian television space.
\end{abstract}

\section{Introdução}

A linguagem é sinônimo de interação e, dessa forma, é também um modo de produção social; ela não é neutra e nem inocente (BRANDÃO, 2012). Dessa forma, não

\footnotetext{
* Licenciado em Letras-Português pela Universidade Federal de Pernambuco (UFPE). gabriel.n santana@live.com

${ }^{* *}$ Doutora em Semiótica e Linguística (USP/Paris X). Professora Associada IV do Setor de Linguística (UFPE). mariavirginialeal@gmail.com

${ }^{1}$ Termo empregado por Gruda (2013) e que será explicado e utilizado no decorrer deste trabalho.
} 
há por que acreditar que piadas são meramente inocentes ou não possuem razões para ofensa, pois uma simples piada está constituída por discursos que circundam e reafirmam determinadas práticas sociais em um dado tempo e em uma dada sociedade. Também dessa forma afirma Gruda (2013, p. 224):

as piadas não podem ser consideradas como instrumentos de linguagem meramente lúdicos ou tão somente a serviço da indústria do entretenimento, as piadas, majoritariamente, representam exatamente o que querem dizer, seja para criticar os costumes sociais [...], ou para ofender e/ou promover determinados grupos sociais.

Dito de outra forma, sempre há uma ideologia que circunda uma expressão da linguagem, desde um poema até uma piada aparentemente "inocente". Maingueneau (2013) afirma que nenhuma produção de enunciado pode acontecer sem uma justificativa; de uma forma ou de outra, o enunciado justifica a forma como se apresenta, isto é, nenhum ato de enunciação ocorre sem dentro dele mesmo explicarse, sem demonstrar o porquê de tal produção de sentido. Em meio a isso, ganha relevância o conceito de humor politicamente incorreto, sendo esse um humor que tenta transgredir o que se tem estabelecido como um comportamento linguístico politicamente correto $^{2}$. É com essa concepção que Gruda (2013) trabalha com os conceitos de humor politicamente incorreto crítico e humor politicamente incorreto acrítico. O primeiro tipo de humor, que tenta subverter determinada ordem social vigente, muitas vezes, tentando desestruturar determinadas práticas de opressão; já o segundo não assume esse tipo de compromisso subversivo, pelo contrário, apenas reproduz discursos atrelados a estigmatizações de grupos sociais.

\footnotetext{
${ }^{2}$ Fiorin (s.d.) define a linguagem politicamente correta como "a expressão do aparecimento na cena pública de identidades que eram reprimidas e recalcadas: mulheres, negros, homossexuais, etc." O autor entende que se tem com ela o objetivo de "combater o preconceito, proscrevendo-se um vocabulário que é fortemente negativo em relação a esses grupos sociais".
} 
A partir disso, podemos afirmar que se um humor que seja transgressor não estiver embebido de nenhuma reflexão, isto é, não levar consigo a crítica e a autocrítica, se aproximará de um humor politicamente incorreto acrítico. E é nesse humor que se nota uma razão para preocupação, pois uma subversão sem autorreflexão, ou sem estar aliada a uma crítica e autocrítica, pode estar a serviço apenas de um senso comum, a serviço de uma moral predeterminada que não questiona seus próprios valores. Quando esse tipo de humor se encontra em contextos midiáticos de âmbito nacional, o problema se amplia e se fazem necessárias reflexões teóricas. Visando possibilitar tais reflexões, este trabalho ainda procura questionar, a partir das conclusões da análise, qual o papel social que vem sendo desempenhado por programas de humor presentes na mídia televisiva brasileira atualmente.

\section{Procedimentos metodológicos}

É relevante destacar que o artigo aqui desenvolvido se fundamenta num trabalho de análise de dados. De tal maneira, fez-se necessária a coleta de um corpus para se observar a presença do humor politicamente incorreto dentro da mídia televisiva. Poderemos perceber, por meio da análise desse corpus, a articulação entre língua e ideologia - o Discurso (ORLANDI, 2007). Através de uma base de estudos da Análise do Discurso, especialmente a de corrente francesa (AD), serão trabalhados alguns conceitos para uma melhor compreensão dos eventos que ocorrem no humor brasileiro em relação aos discursos do politicamente incorreto.

Analisaremos qualitativamente alguns episódios que aconteceram em programas do humorista e apresentador de talk-show Danilo Gentili , nos quais se

\footnotetext{
${ }^{3}$ Natural de Santo André (SP) e nascido no ano de 1979, Danilo Gentili é um comediante de grande fama entre a juventude brasileira. $\mathrm{O}$ artista ganhou reputação como um dos representantes da "nova direita brasileira" após algumas declarações sobre seu posicionamento político, que ocorreram, em especial, desde que passou a ter seu programa de talk-show na emissora de TV Bandeirantes chamado Agora é Tarde. Junto a seu posicionamento político deixado claro, Gentili também demonstrou em seus anos de carreira sua adesão a discursos de opressão a determinados grupos sociais - como veremos
} 
podem notar casos explícitos de repúdio aos Direitos Humanos ou a qualquer manifestação de apreço a tais direitos. Serão expostos também alguns exemplos de piadas preconceituosas ${ }^{4}$ proferidas por Gentili - tipo de evento que acontece corriqueiramente e pelo qual o humorista ficou bastante conhecido. De forma geral, os dados deste trabalho são compostos por exemplos de descaso aos direitos humanos, ao politicamente correto e também de ofensas e agressividade a manifestações ou posicionamentos ideológicos contrários.

O corpus é composto por três entrevistas. Duas delas foram ao ar no ano de 2013, ambas ocorrendo no antigo programa do humorista e apresentador Danilo Gentili, chamado "Agora é Tarde". As duas entrevistas em questão foram colhidas de programas feitos com o artista Lobão, do dia 08 de maio; e com o economista e colunista da Isto é, da Gazeta do Povo e ex-colunista da Veja, Rodrigo Constantino, do dia 10 de dezembro. Temos como razão para a escolha dessas duas entrevistas: (i) tanto o aspecto de semelhança ideológica entre ambos os entrevistados, bastante conhecidos, dentre algumas outras "celebridades", por vir representando a nova juventude reacionária brasileira - é por essa razão que o enfoque de nossas análises será não só em como Danilo Gentili propaga discursos do politicamente incorreto acrítico, mas também em como o apresentador compactua e dissemina tais discursos em seus programas -; (ii) como também a breve distância de tempo entre ambas as entrevistas, ocorridas em meio a um período de turbulência política do país, entre as manifestação de junho de 2013 e as eleições de 2014.

mais à frente. Por tais fatores, faz-se justificável a escolha de Gentili para uma análise de discursos do humor politicamente incorreto neste artigo.

${ }^{4}$ Dentre as conceituações dadas pelo Dicionário Houaiss da língua portuguesa ao termo "preconceito", encontra-se como primeira definição: "1 qualquer opinião ou sentimento concebido sem exame crítico 1.1 ideia, opinião ou sentimento desfavorável formado sem conhecimento abalizado, ponderação ou razão" (HOUAISS, 2001, grifo nosso). É precisamente no que diz respeito à criticidade (ou sua ausência) que se monta nossa teorização acerca do humor politicamente incorreto, como explicitaremos na subseção 4.1. 
A terceira entrevista diz respeito a uma edição do programa em 2014 com a candidata à presidência na última eleição pelo PSOL, a ex-deputada Luciana Genro. Buscando ir além da observação de comportamentos politicamente incorretos apenas entre pares ideológicos, a inclusão dessa terceira entrevista teve como objetivo trazer também um exemplo de como se dá o politicamente incorreto frente a um direcionamento ideológico contrário. Com a intenção de complementar as análises dessas três entrevistas, foram selecionadas duas publicações de Danilo Gentili na rede social Twitter: uma no ano de 2012, quando o apresentador proferiu uma piada racista a um afrodescendente; e outra em janeiro de 2015, quando o humorista proferiu um xingamento à ex-presidente Dilma Rousseff. Coletamos justamente esses dois tweets por serem precisamente os dois que tiveram o maior alcance de "curtidas" e "retweets" até então na conta do humorista.

\section{Humor em sua origem: o riso}

Dentro da mídia humorística televisiva, podemos, por diversas vezes, encontrar elementos do humor cínico - que seria algo aproximado do humor praticado na Grécia antiga, em que se tentava expor os "vícios da sociedade", dando julgo de valor e pretendendo impor uma moral para a sociedade. Porém, esse humor de caráter cínico - da mesma maneira que se estrutura o cinismo contemporâneo - procura moralizar com a intenção de justificar a imoralidade dos preconceitos, das desigualdades e das opressões arraigadas no corpo social (ZIZEK apud GRUDA, 2013). Podemos notar nas expressões de humor cínico contemporâneo, por exemplo, alguns discursos de que o negro não deve se sentir incomodado por ser constantemente caracterizado por feições sexuais extremadas, de que a mulher feia deve ficar feliz por ser assediada e de que o cidadão corrupto se torna bem-sucedido.

Os risos provindos dos chistes do humor politicamente incorreto acrítico procuram neste tipo de humor mecanismos que possam inibir ou enganar a censura 
(MALISKA, s.d.), isto é, ocorrem processamentos do "inconsciente" para afastar a influência do "superego" e aceitar uma ofensa ou discriminação como algo normal ou banal. Entende-se disso que há um movimento de naturalização de discursos do politicamente incorreto acrítico e que tais discursos se fundamentam no argumento de que são banais as discussões propostas pelo politicamente correto. As "frases de espírito" - também conhecidas como "chistes", já citados anteriormente - representam espaços abertos na repressão do "superego", em que existem brechas para que vontades e impulsos do inconsciente sejam percebidos pelo consciente, sendo tais frases de espírito divididas em inofensivas e tendenciosas (FREUD, 1905).

As frases de espírito tendenciosas caracterizam-se por ocultarem impulsos cínicos ou sádicos. Já as inofensivas restringem-se a um jogo técnico de fonemas, palavras ou sintagmas. Porém, a frase de espírito inofensiva também tem a possibilidade igual de relacionar críticas, mesmo estas sendo não tão facilmente notáveis por um coenunciador ${ }^{5}$. A partir disso, Gruda (2013) entende que as frases de espírito tendenciosas, por seu caráter mais perceptível, afirmam, mesmo que por metáfora, suas próprias visões de mundo, as quais não poderiam ser produzidas abertamente por causa das pressões do superego construídas pelas relações sociais. Com efeito, essas frases trazem consigo o que correntemente é interdito ou proibido de ser enunciado.

Pelo caráter das frases de espírito de trazerem consigo o que correntemente é interdito ou proibido de ser enunciado publicamente, depreende-se que um humor politicamente incorreto acrítico, considerado em suas realizações como frases de espírito tendenciosas ou inocentes - vale lembrar que estas também podem ter seu tom cínico -, são nada muito além que conceitos, valores e preconceitos que estão no

\footnotetext{
${ }^{5}$ Termo adotado na tradução do livro Análise de textos de comunicação, de Maingueneau (2013), para aquele que figura a cena de enunciação junto ao enunciador, ambos sendo coenunciadores igualmente relevantes e ativos nessa mesma enunciação.
} 
inconsciente coletivo de uma determinada sociedade. São então, de tal maneira, discursos que não são produzidos tão abertamente por repressão dos avanços de questões de direitos humanos, tanto através das lutas de diversas minorias como no meio intelectual ao redor do mundo. Evidenciaremos no corpus exemplos de chistes de Danilo Gentili que tornam clara a sua filiação ideológica, e, através disso, buscaremos entender como se dá o processo de perpetuação de valores opressivos vigentes em seu programa televisivo.

\section{Humor enquanto prática social através da linguagem}

Devemos entender os processos linguísticos como ações sobre o mundo e sobre as pessoas que circundam o enunciador (BRANDÃO, 2012), isto é, a linguagem verbal humana processa-se sistematicamente não apenas por seus signos linguísticos, mas também por uma série de "investidas" socioideológicas, provindas de um determinado enunciador. Enquanto ocorre tal processo, chamado enunciação, há outros discursos, envoltos por sentidos de determinadas formações discursivas, agindo de forma dialógica na produção de sentido do enunciado. Tal conceituação faz-se importante para os dois próximos subtópicos, pois, a partir do entendimento da língua enquanto interação social, poderemos perceber que ela pode servir para (4.1) uma falsa transgressão de valores tradicionais; e também pode ser uma constante (4.2) prática de perpetuação de ideologias dominantes.

Em meio a tudo isto, não é plausível entender uma piada como um mero ato cujos efeitos mais profundos não são calculados. Segundo Gruda (2013), o discurso materializado em simples piadas não é, por definição, desprovido de politização ou de ideologia; está intrinsecamente envolto de intenções silenciadas por pressões socioculturais. Também acerca da linguagem, Maingueneau (2008) afirma que o discurso contribui para a estruturação de todas as dimensões das relações sociais, e essas também o constituem e o cerceiam. Também declara que o discurso é uma prática 
social - mais especificamente, é uma prática discursiva - e, com isso, não apenas representa algo no mundo, mas significa e constitui-se nele. Com efeito, podemos entender que a linguagem, seja em uma piada, seja em um debate político, não é apenas uma expressão descompromissada, mas um ato de significação sobre o mundo. Por isso mesmo, é esperado de um sujeito autocrítico que seja responsável e tenha ética nas suas práticas sociais. Dessa maneira, depreendemos que um humor politicamente incorreto acrítico não pode ser caracterizado como algo banal e quotidiano, pois tal prática faz-se prejudicial para um debate a respeito de uma solução para as desigualdades das relações de poder da atualidade.

\subsection{A transgressão a serviço do senso comum}

Dentro de uma visão dialética dessa questão, um discurso politicamente incorreto existe por se contrapor a um discurso anterior do politicamente correto (GRUDA, 2013). Isto é, o politicamente incorreto se caracteriza como nada mais que uma volta à velha tradição de preconceitos e opressão, ou melhor, caracteriza-se por transgredir o avanço alcançado internacionalmente dentro dos direitos humanos.

A ideologia dominante organiza-se de forma lógica e coerente de representações (ideias e valores) e também de normas, regras ou condutas (CHAUÍ, 1984), ou seja, baseando-se em uma concepção marxista de ideologia, pode-se entender que há mecanismos que ajudam a perpetuar uma ideologia dominante, tornando-a comum e aceitada facilmente, ou, sendo mais preciso, naturalizando-se como verdade.

Gruda (2013) explicita que mesmo a piada de humor politicamente incorreto acrítico, desafiando o convencional, apenas reafirma uma não convencionalidade e, de tanto afirmá-la, torna-se também o convencional e tradicional, naturalizando-se e entrando no senso comum. Assim, o politicamente incorreto acrítico se faz como o tradicional e ideologicamente dominante a partir do momento que se torna o comum, o naturalizado. Com isso em vista, compreende-se que uma piada de humor 
politicamente incorreto acrítico transparece uma ideologia dominante e serve como instrumento de perpetuação, "um instrumento de dominação de classe pela qual a classe dominante faz com que suas ideias passem a ser ideias de todos" (BRANDÃO, 2012, p. 21).

\subsection{Discursos enquanto práticas de perpetuação ideológica}

Retomando o subtópico inicial, pode-se entender que, em meio a inúmeras práticas sociais, há as práticas discursivas. Tendo o texto como objeto empírico e o discurso como objeto teórico, tomando o discurso como prática social, e, a partir de tais conhecimentos, podendo afirmar que a prática só existe na ideologia através de uma ideologia (ALTHUSSER apud BRANDÃO, 2012), o humorista ter como respaldo a afirmação de que uma piada, não necessariamente, representa algo além de si própria é algo que possui uma sustentação questionável, pois o conteúdo de tal humor, mesmo estando dentro de intenções próprias e dentro de um universo global humorístico, estará sempre ligado estreitamente ao fazer/agir socialmente (POSSENTI, 1995; 2010).

Como afirma Gruda (2013, p. 220), as piadas do humor politicamente incorreto acrítico se formão de uma forma bastante cínica, investida de uma agressividade intensa e explícita, se respaldando "especialmente na argumentação de que 'piadas são só piadas' e de que a liberdade de expressão é alguma coisa de caráter completamente ilimitado". Tal apoio na liberdade de expressão mostra-se infundado e embebido de desinformação, ou talvez até de uma má interpretação do que se tem por liberdade de expressão. Tomemos o que há escrito sobre liberdade de expressão na Declaração Universal do Direitos Humanos proclamada em Assembleia Geral pela ONU (Organização das Nações Unidas) em dezembro de 1948:

Todo ser humano tem direito à liberdade de opinião e expressão, este direito inclui a liberdade de, sem interferência, ter opiniões e de procurar, receber e transmitir informações e ideias por quaisquer meios e independentemente de fronteiras. [...] No exercício de seus 
direitos e liberdades, todo ser humano estará sujeito apenas às limitações determinadas pela lei, exclusivamente com o fim de assegurar o devido reconhecimento e respeito dos direitos e liberdades de outrem (UNIC Rio apud GRUDA, 2013).

Entende-se dessa passagem da Declaração que a liberdade individual de expressão - tão usada como argumento para o humor politicamente incorreto - não dá o direto de invadir a liberdade do outro, não abre concessão de ofender e agredir, infringindo o direito de outrem.

De maneira geral, os discursos estão submetidos a formas sociais de organização e a regras vigentes numa determinada sociedade, assim como o discurso é orientado, desenvolvendo-se de maneira linear; e também é uma forma de ação sobre o mundo, pois falar é uma forma de ação sobre o outro e não apenas uma representação, mas sim uma prática discursiva (MAINGUENEAU, 2013). Dessa forma, ao expormos nossa opinião ao mundo, não estamos jogando signos ao vento, mas estamos realizando uma prática social e estabelecendo relações de poder. Nossas práticas discursivas não só não são meramente arbitrárias, isentas de propósito ideológico, como também são atravessadas por uma cadeia de interdiscursos, ou um "universo discursivo", que constitui subjetivamente a "formação discursiva" de cada indivíduo social (MAINGUENEAU, 2008, p. 33). De outro modo, pode-se dizer que um discurso nunca começa nele próprio, assim como um preconceito não nasce $a b$ ovo, mas, na verdade, materializa-se de modo recorrente em diferentes textos de forte representação social, construindo assim discursos historicamente marcados na esfera de uma memória social. Depreende-se disso que um sujeito que produz um humor politicamente incorreto e não reflete sobre seu processo de criação corre, inevitavelmente, o risco de estar apenas reproduzindo ideologias que dominam as superestruturas sociais; e dessa maneira, em vez de estar quebrando paradigmas sociais, estará perpetuando preconceitos e valores históricos de opressão. 


\section{Análise dos dados}

Em primeiro lugar, é de suma relevância explicar a origem e a organização dos dados deste trabalho. Não há divisão explícita entre os dados e suas análises neste artigo; isto é, a apresentação dos exemplos se dará concomitantemente com uma investigação reflexiva. Os dados são majoritariamente compostos por duas entrevistas que foram ao ar no ano de 2013, que ocorreram no antigo programa do humorista e apresentador Danilo Gentili chamado "Agora é Tarde". Foram colhidas as entrevistas feitas com o artista Lobão, do dia 08 de maio; e com o economista e colunista da Isto é, da Gazeta do Povo e ex-colunista da Veja, Rodrigo Constantino, do dia 10 de dezembro. Buscando complementar algumas análises aqui feitas, foram também incorporados ao corpus: um trecho da entrevista de 2014 com a candidata à presidência na última eleição pelo PSOL, a ex-deputada Luciana Genro; além de dois textos publicados por Gentili na rede social Twitter, um no ano de 2012 quando o apresentador proferiu uma piada racista a um afrodescendente, e outro em janeiro de 2015 quando o humorista proferiu um xingamento à ex-presidente Dilma Rousseff.

Os subtópicos a seguir estão estruturados de forma que possamos, primeiramente, perceber (5.1) os preconceitos demonstrados por Danilo Gentili de forma mais explícita; (5.2) seus posicionamentos acerca dos Direitos Humanos e do Politicamente Correto; (5.3) e ainda seu comportamento frente a posicionamentos políticos contrários. O que se espera da análise de tudo isso é podermos refletir e entender um pouco do papel de tais práticas politicamente incorretas acríticas para uma perpetuação de ideologias de opressão a grupos historicamente estigmatizados no Brasil.

\subsection{Preconceitos explicitamente efetuados}

O humorista de stand-up, ex-integrante do programa humorístico CQC, e atual apresentador do programa de talk-show chamado The Noite possui nacionalmente 
uma grande notoriedade por suas piadas de "humor negro" - termo comumente utilizado pelo humorista e seus apoiadores - e seu repúdio aos direitos humanos e a manifestações contrárias ao seu tom politicamente incorreto. Podemos tomar como exemplo o caso de outubro de 2012 em que Gentili postou em sua conta do Twitter a seguinte mensagem (Exemplo 1): “Sério @LasombraRibeiro vamos esquecer isso... Quantas bananas vc quer pra deixar essa história pra lá?" (GONÇALVES, 2012). O sujeito a quem Gentili se referia era um homem afrodescendente de cidadania brasileira que perguntou ao apresentador, pela rede social em questão, se ele poderia mandar algum e-mail da Rede Bandeirantes para que ele pudesse enviar uma cópia da denúncia de racismo que ele apresentaria ao ministério público no dia seguinte.

Casos como o citado acima são justificados pelo apresentador de diversas maneiras. Enquanto estava sendo entrevistado num programa de Roberto Justus na Rede Record, Danilo Gentili justificou suas piadas de tom racista com a comparação entre "piadas com loiras" e "piadas com afrodescendentes", com o argumento de que, se é permitido piadas com loiras e isso não é considerado preconceito pela sociedade em geral - pelo fato de "todos saberem que loiras não são realmente burras" -, não é preconceito chamar afrodescendentes de macacos. Ao usar essa comparação como argumento para tornar legítimo seu "direito" de fazer piadas racistas, o humorista põe a prova não só seu desconhecimento acerca da origem histórica arraigada de machismo das piadas com loiras ${ }^{6}$; como também mostra sua completa desinformação acerca da historicidade dos problemas sociais envolvendo a etnia afrodescendente -

\footnotetext{
${ }^{6}$ Não se sabe exatamente em que tempo teve início as piadas com loiras, porém sabe-se que, desde as primeiras estrelas loiras de Hollywood, há uma imensa construção social do estereótipo de loiras burras. O que é fácil de perceber é que tais tipos específicos de preconceitos surgem apenas para o gênero feminino: não se vê fazerem piadas com homens loiros; nem xingar sogros de "linguarudos" ou associálos com demônios - ou algum tipo entidade má; nem dizer que os homens são complicados de entender e agradar. São nessas visões unilaterais acerca de defeitos que são humanos e não de gênero - nem de uma natureza feminina - que pode ser percebida uma formação discursiva machista (BAIRROS, s/d).
} 
não apenas no Brasil, mas em todo o mundo. Tomemos a definição do dicionário Houaiss (2001) sobre o racismo:

Racismo: 1. conjunto de teorias e crenças que estabelecem uma hierarquia entre as raças, entre as etnias. 2. doutrina ou sistema político fundado sobre o direito de uma raça (considerada pura e superior) de dominar outras. 3. preconceito extremado contra indivíduos pertencentes a uma raça ou etnia diferente, ger. considerada inferior. 4. atitude de hostilidade em relação a determinada categoria de pessoas. (HOUAISS, 2001).

De maneira geral e objetiva, pode-se dizer que o racismo não se dá simplesmente por ofender pessoas de etnia negra, mas por discursos que procuram estabelecer uma ordem hierárquica entre as raças e etnias, discursos esses que têm raiz histórica e que contribuem para a atual desigualdade étnica, ou seja, algo bem maior e mais complexo que uma mera ofensa.

Por volta do vigésimo minuto de entrevista com o cantor Lobão, o entrevistado levanta o seguinte argumento acerca dos movimentos artísticos e dos estudos culturais acadêmicos no Brasil (Exemplo 2): “O que eu acho que é nefasto para todos nós é acreditar num Papai Noel horroroso. Tipo assim: que ter preguiça é bacana, que ser precário é legal, que ser balão de agulha - aquele que dá uma espetada e leva no buraco - é uma coisa muito esperta". Imediatamente após a última frase do que foi dito pelo artista, surgem gargalhadas vindas dos integrantes da banda do programa e Danilo Gentili abre amplo um sorriso no rosto e incisivamente acena a cabeça verticalmente em sinal de aprovação à afirmação. Sem se fazer necessário um comportamento verbal, podemos perceber que, a nível paralinguístico, se constitui aqui uma realização de chistes tendenciosos e direcionados ideologicamente. As expressões de risibilidade apresentadas pelos integrantes do programa estão ligadas ao humor homofóbico proferido pelo cantor entrevistado, humor esse pelo qual Danilo Gentili ratifica um 
efeito de sentido de aprovação por meio de dois recursos paraverbais explícitos, o sorriso e o aceno de cabeça.

Analisando tal prática discursiva, percebe-se que, além de tais preconceitos serem bastante prejudiciais a toda uma causa da luta social do movimento LGBT, o acontecido nesse trecho de entrevista mostra-se mais grave ainda, pois o entrevistado logo em seguida relaciona essa fala com o argumento de que os estudos acadêmicos e aqueles que fazem ciência no Brasil são motivados por "besteiras" e, em maior parte, levam a um desperdício de tempo. Entendendo o humor politicamente incorreto acrítico como uma transgressão a serviço do senso comum (item 4.1), isto é, uma forma de dominação pela qual a classe dominante faz com que suas ideias passem a ser ideias de todos (BRANDÃO, 2012), verificamos que a atitude do cantor - junto ao apoio já esperado do entrevistador e da banda do seu programa - pode também ser entendida como fascista, pois, ao intentar por dizer o que é o comportamento natural, correto e "neutro", acaba por deslegitimar e colaborar com o apagamento da voz de determinado grupos sociais - tendo em vista que, a partir do momento que ele deslegitima movimentos culturais e sociais como este, ele está contribuindo para a falta de representação de uma parcela da população, apagando a voz desse grupo social.

De maneira geral, é necessário destacar que tais problemas são relativos não só ao preconceito exposto por Danilo Gentili, mas também por seu apoio ao preconceito de seus entrevistados. Isso mostra que o apresentador do The Noite não apenas dissemina discursos de teor politicamente incorreto, mas seu próprio discurso se faz desses outros a quem ele apoia e com os quais compactua, ou seja, um discurso nunca começa nele próprio, antes mesmo deste discurso há sentidos que sustentam os sentidos que se constroem nele (ORLANDI, 2007). 


\subsection{Sobre os Direitos Humanos e o Politicamente Correto}

Por volta do nono minuto de entrevista com Rodrigo Constantino, o entrevistado, conversando sobre o livro que acabara de lançar, faz a seguinte afirmação acerca do politicamente correto (Exemplo 3): “Hoje a gente tem um problema muito sério que eu vejo que é o seguinte: é o politicamente correto, que é bastante falado nesse livro, que o programa de vocês está aí, assim como uns outros pra confrontar". E o entrevistador responde em tom de sarcasmo: "Vamos ver até quando" - fazendo irromper uma risada do entrevistado e de si próprio; percebe-se neste enunciado que Gentili faz piada com os vários processos judiciais que passou, mostrando um tom de despreocupação e nenhum arrependimento pelo que já fez.

Pode-se notar que a impressão expressa pelo colunista da Isto É sobre o Politicamente Correto é unicamente a de um problema, problema esse que tem como encargo atrapalhar sua liberdade de expressão. Após esse trecho da entrevista, Constantino continua suas afirmações acerca de sua opinião sobre o politicamente correto:

\section{(Exemplo 4)}

Você tem essa questão do politicamente correto que suspende qualquer tipo de julgamento. Hoje em dia passa a ser uma coisa horrorosa você emitir um julgamento sobre certas coisas morais, estéticas ou de valores. Então eu sou obrigado, por exemplo, a suspender qualquer tipo de opinião em relação a certas coisas se não eu sou um sujeito preconceituoso, elitista, não sei o quê.

Mais uma vez, a mesma confusão a respeito do politicamente correto e da liberdade de expressão. Como já foi salientado no item 4.3, tal opinião de que o politicamente correto tem como incumbência cercear a liberdade individual de um sujeito mostra-se pouco fundamentada, e, indiretamente, expressa a desinformação de Danilo Gentili e seu entrevistado sobre o que concerne ao politicamente correto. 
Passando para a entrevista com o artista Lobão, em torno do décimo primeiro minuto de conversa, podemos notar o mesmo nível de desinformação sobre tais questões, porém, desta vez, a respeito dos direitos humanos e do que é defendido nestes:

\section{(Exemplo 5)}

Uma coisa que é também super assim: Neguinho é a favor dos direitos humanos, num sei o que, e fala assim: 'seu branquela playboy classe-média'. Peraí, eu sou classe média, é algum downgrade? O que eu tenho que ser? Eu tenho que me esculachar mais pra ser relevado nesse país? E todo mundo tem que ser pobre pra ser gente fina?

Também é relevante lembrar que é neste tipo de pensamento "vitimista" burguês que residem e surgem inúmeros preconceitos contra as camadas mais pobres e estigmatizadas que necessitam de assistência do Estado. Preconceitos esses que se fundamentam no entendimento de que a elite branca burguesa heteronormativa também é vítima de preconceitos, pois eles não têm assistência nem auxílio ou atenção do Estado. Contudo, esquece-se de salientar que não há historicidade de sofrimento e opressão, não existem reais relações de poder dentro da sociedade que apontem desigualdade em relação a essas supostas minorias; não há nenhuma construção social de subcidadania e nem há uma formação periférica desses grupos sociais, mas, pelo contrário, tais grupos estão historicamente localizados no cerne de atenção da sociedade (SOUZA, 2012).

O que se mostra alarmante quanto a essa questão é o extenso número de seguidores dos discursos que estão envoltos nesse tipo de humor, um grande número de jovens que se declaram revoltados, por exemplo, com a opressão que sofrem por serem heterossexuais brancos de classe-média no Brasil. A influência deste tipo de mídia humorística televisiva vem causando a naturalização de discursos que perpetuam ainda mais valores de ideologias dominantes numa sociedade que já é 
profundamente reacionária e conservadora (Ibidem). A disseminação midiática desse humor politicamente incorreto acrítico estimula, desse modo, a produção de argumentos semelhantemente infundados por diversas esferas do senso comum.

\subsection{Desrespeito e desinformação acerca de opiniões contrárias}

Foi bastante comum observarmos durante nossas análises reações agressivas a opiniões contrárias vindas de Danilo Gentili, não apenas em seu programa de televisão, mas também em suas contas de redes sociais. São inúmeras as contraofensivas direcionadas às piadas de humor preconceituoso do humorista, e em todas há um retorno de agressividade. Para demonstrar tal fato, tomemos um trecho da entrevista com Rodrigo Constantino - por volta do décimo quarto minuto, em que o colunista da Gazeta do Povo fazia algumas afirmações sobre a esquerda no Brasil (Exemplo 6): “O quão esquisito não é a gente ver Jean Wyllys dizendo que defende o 'grupo todo de gays' usando uma boina no estilo Che Guevara. É muita ignorância". E então o entrevistador acrescenta: “Outro dia eu vi isso e disse: ‘Meu! Jean Wyllys vestido de socialista seria como um judeu vestido de nazista'"'.

Tais afirmações apontam as filiações ideológicas do entrevistado e do entrevistador, filiações essas que demonstram a desinformação acerca do que se tem por esquerda e por socialismo no cenário político brasileiro e mundial. Tais argumentos se baseiam no discurso de que a perseguição a gays e lésbicas foi algo exclusivo de regimes ditatoriais comunistas, quando, na verdade, sabe-se que houve o genocídio de homossexuais e pessoas trans em todos os continentes do planeta durante o século XX, inclusive em nações ditas democráticas ou livres; ou ainda baseiam-se na ideia de que o socialismo é impreterivelmente algo maquiavélico e nefasto, e que tem intenções de dominação para algo danoso à humanidade. Observa-se, assim, que o desrespeito e a ofensividade do apresentador não se restringem apenas a opiniões contrárias e a contraofensivas de seu humor. $O$ ex-CQC possui demasiada 
popularidade por suas opiniões e seu posicionamento político de direita, e, quando contrariado e questionado sobre seu humor, põe-se a atacar ideologias contrárias e a propagar histórias para difamar posicionamentos políticos com os quais não é de acordo.

O mesmo tipo de afirmação é encontrado em diversas declarações do apresentador, como, por exemplo, numa entrevista com a ex-presidenciável Luciana Genro, em que Gentili tentava demonstrar que as experiências que se autodenominavam comunistas deram errado. E então a ex-candidata o questiona sobre suas afirmações:

\section{(Exemplo 7)}

Genro: - E o capitalismo? Tu acha que acertou alguma?

Gentili: - Eu acho que bem mais.

Genro: - Ah, é? Por que tu estás numa situação privilegiada. Agora, se tu tivesse lá na ocupação que eu visitei hoje, na ocupação Anchieta onde o pessoal está morando nuns barracos, entendeu? Tu ias achar que o capitalismo fracassou também.

Gentili: - É que, se fosse um sistema comunista, eles não estariam mais morando lá, eles estariam sendo fuzilados no barraco.

Novamente, percebe-se, nos argumentos do politicamente incorreto acrítico formulados por Danilo Gentili, ataques à deputada federal e à sua filiação ideológica que se fundamentam, correntemente, numa histeria de medo de "um Estado perverso" que possa cercear suas liberdades individuais, e em discursos de pânico a um sistema socioeconômico totalitário e controlador. Isto é, há uma confusão nos discursos de Danilo Gentili entre o que são as pautas socialistas na contemporaneidade e o que houve nos regimes ditatoriais da União Soviética e no início da revolução cubana; constituindo-se, assim, nos discursos do apresentador, uma generalização de diferentes contextos e momentos históricos, com fins de atacar posicionamentos políticos contrários ao seu. 
Ofensas e ataques a posicionamentos políticos opostos são largamente banais para o humorista. Tem-se como um exemplo próximo à época o caso em que Danilo Gentili proferiu publicamente um xingamento à atual presidente do Brasil pelo Twitter (Exemplo 8): “Vai se fude! [sic] RT @dilmabr: O nosso povo votou em nós porque acredita em nossa capacidade e em nossa honestidade de propósitos". Passando mais uma vez para a entrevista com Lobão, há um momento na entrevista - em torno do oitavo minuto - em que o cantor, expressando seu ódio pelo academicismo e seus estudos no Brasil, faz a seguinte declaração (Exemplo 9): “Essa intimidação dessa esquerda fajuta de te chamar de direita... Olha, é frouxo! Câmera! - fala o cantor, chamando a câmera pra um close - $\mathrm{O}$ intelectual de esquerda é um campeão de "punheta de pau mole'". E então Gentili irrompe em gargalhadas e acrescenta: "Concordo com você [...]" e logo após faz uma piada de cunho sexual com um integrante de seu programa.

Atitudes como as demonstradas no trecho de entrevista e no tweet de Gentili mostram, mais uma vez, como o apresentador encara os discursos que circundam a esquerda. Percebe-se que, além de utilizar ofensas, também vê os estudos de esquerda no Brasil como algo estúpido, e, mais ainda, delegando aos intelectuais de esquerda um papel de "fracos" ou "covardes". Verifica-se aqui o uso de um argumento falacioso Ad Hominem ${ }^{7}$, direcionando o debate para questões que envolvem a quantidade de masculinidade do objeto que está sendo atacado. Esse tipo de discussão acerca de quem é mais "macho", além de misógino (por enxergar os traços de gênero mais femininos como algo de "marica" ou fraco), não é coerente com um debate a respeito de questões políticas.

Além de tudo isso, este ataque pode ser entendido como um apelo à ideia de que o que há nas universidades públicas no Brasil é inválido por ser influenciado por

\footnotetext{
${ }^{7}$ Esse tipo de falácia se constitui em atacar o adversário, ressaltando características que supostamente seriam defeitos deste (WALTON, 1998).
} 
uma "doutrinação marxista" do Ministério da Educação (MEC), especialmente devido aos anos de governo do Partido dos Trabalhadores (PT). Depreende-se que, para poder embasar-se sem correr riscos de ser refutado em nível acadêmico, o apresentador utiliza tal argumento conspiracionista de que as universidades brasileiras estão repletas de alunos e professores marxistas doutrinados pelo MEC durante os treze anos de governo do PT. Por conveniência e adequação às suas opiniões politicamente incorretas acríticas, torna-se muito corriqueiro ver ofensivas de Danilo Gentili à esquerda e ao socialismo como um todo. E, dentro de suas afirmações, pode-se notar evidente desinformação acerca de conceitos ligados ao materialismo histórico e a concepções políticas ditas socialistas, ou de esquerda.

\section{Considerações finais}

Através da reflexão sobre a influência que programas humorísticos como o de Danilo Gentili exercem sobre parte da população que é influenciada por conceitos de ideologias dominantes - em especial o público jovem -, podemos compreender que há uma massiva disseminação dos discursos do politicamente incorreto acrítico. E tais discursos alcançam uma enorme popularidade - principalmente nas camadas mais abastadas da classe média brasileira - possivelmente por tal humor possuir um caráter antiacadêmico, sendo, por meio de tal discurso mais superficial, um humor com mais fácil compreensão/adesão popular.

É imprescindível destacar o fato de que a naturalização dos discursos de enaltecimento do politicamente incorreto acrítico nada mais é que relações de poder que existem há muito tempo nas sociedades em torno do mundo, mas que, atualmente, vêm sendo postas em voga como o "belo" ou o correto a ser feito. Tais discursos têm a capacidade de cativar grande parte da população por serem compostos por conhecimentos que rondam em torno do senso comum, ou seja, não desafiam a ordem estabelecida na sociedade. Muito pelo contrário disto, estes discursos compõem-se de 
inúmeras vozes que tem como finalidade manter as relações de poder vigentes na sociedade atual.

Sendo esses discursos parte de formações ideológicas que pretendem perpetuar relações de opressão a massas historicamente estigmatizados, espera-se que, com base nas análises aqui propostas: possamos compreender parte da função do humor politicamente incorreto na naturalização de discursos contra os direitos humanos e contra grupos sociais historicamente oprimidos; além de possibilitar uma reflexão preliminar acerca de qual seria o papel social desempenhado pela mídia televisiva brasileira atualmente e qual seria a função que almejamos alcançar para nossa mídia enquanto república plural e democrática.

\section{Referências Bibliográficas}

AGORA é Tarde 10/12/13 - Completo - Rodrigo Constantino - Band. Disponível em: https://www.youtube.com/watch?v=kpPIM74u75Y. Acesso em: 12 fev. 2018.

BRANDÃO, H. N. Introdução à análise do discurso. 3. ed. Campinas: Editora da Unicamp, 2012.

BAIRROS, L. Nossos feminismos revisitados. Disponível em: http://www.bibliotecafeminista.org.br/index.php?option=com remository\&Itemid=5 $\underline{6 \& f u n c=s t a r t d o w n \& i d=206}$. Acesso em: 10 jul. 2015.

CHAUÍ, M. O que é ideologia. São Paulo: Brasiliense, 1984.

DANILO Gentili entrevista Lobão no Agora é tarde - 08/05/2013. Disponível em: https://www.youtube.com/watch?v=ykS1vwjNmR0. Acesso em: 12 fev. 2018.

FAIRCLOUGH, N. Discurso e mudança social. Brasília: Editora Universitária de Brasília, 2001.

FIORIN, J. L. A linguagem politicamente correta. Disponível em: http://www.letras.ufscar.br/linguasagem/edicao01/artigos alinguagempoliticamente correta.htm. Acesso em: 23 mar. 2018. 
FREUD, S. Os chistes e a sua relação com o inconsciente. Rio de Janeiro: Imago Editora.

GONÇALVES, J. A certeza da impunidade: Danilo Gentili oferece 'bananas' a internauta negro pelo Twitter. Disponível em: http://arquivo.geledes.org.br/racismopreconceito/racismo-no-brasil/15760-a-certeza-da-impunidade-danilo-gentili-oferecebananas-a-internauta-negro-pelo-twitter. Acesso em: 25 jan. 2015.

GRUDA, M. P. P. Questionando alguns argumentos-base que sustentam um tipo de discurso humorístico politicamente incorreto. Configurações da crítica cultural, Alagoinhas, v. 1, n. 1, p. 219-233, jan./jun. 2013.

HOUAISS, A.; VILLAR, M. de S.; FRANCO, F. M. de M. Dicionário Houaiss da língua portuguesa. Rio de janeiro: Objetiva, 2001.

MAINGUENEAU, D. Gênese dos discursos. São Paulo: Parábola, 2008.

MAINGUENEAU, D. Análise de textos de comunicação. 6. ed. São Paulo: Cortez, 2013.

MALISKA, M. E.; SOUZA, S. C. L. de. Sobre o humor: um diálogo entre Freud e Possenti. Disponível em: http://linguagem.unisul.br/paginas/ensino/pos/linguagem/eventos/seminario/anais\% 201/Mauricio Maliska Silvana Souza.pdf. Acesso em: 13 mar. 2018.

ORLANDI, E. P. Educação em direitos humanos: um discurso. In: SILVEIRA, R. M. G.. Educação em Direitos Humanos: fundamentos teórico-metodológicos. João Pessoa: Editora Universitária da UFPB, 2007. p. 295-310.

POSSENTI, S. Humor, língua e discurso. São Paulo: Contexto, 2010.

POSSENTI, S. A linguagem politicamente correta e a análise do discurso. Revista de Estudos da Linguagem, Belo Horizonte, v. 3, n. 2, p. 125-142, 1995. Disponível em: http://periodicos.letras.ufmg.br/index.php/relin/article/viewFile/1016/1127. Acesso em: 14 abr. 2018.

SOUZA, J. A construção social da subcidadania: para uma sociologia política da modernidade periférica. 2. ed. Belo Horizonte: UFMG, 2012.

THE NOITE (15/09/14) - Entrevista com Luciana Genro. Disponível em: https://www.youtube.com/watch?v=PBXeEe4KURM. Acesso em: 12 fev. 2018. 
WALTON, D. Ad hominem arguments. Tuscaloosa: University of Alabama, 1998. 